\title{
Practical implementation of the on-board solar photovoltaic for the passenger transportation
}

\author{
Sulaiman Khan ${ }^{\text {a* }}$, Syed Hussain Imran ${ }^{\mathrm{b}}$, Mushtaq Khan ${ }^{\mathrm{b}}$, Numan Khan ${ }^{\mathrm{a}}$ \\ ${ }^{a}$ School of Mechanical and Manufacturing Engineering, NUST, Islamabad, 44000, Pakistan \\ ${ }^{b}$ National University of Science and Technology, Islamabad, 44000, Pakistan
}

\begin{abstract}
The world is highly dependent on the fossil fuels which is exhausting. The transport sector is also a major consumer of the depleting fossil fuel, almost $28 \%$ of the total energy is consumed by the transport sector. Hence Shifting of the road transport on the alternative and renewable energy sources will have a remarkable impact on the stressful use of the oil and gas. This research work investigates the feasibility of solar photovoltaic energy for commercial transportation considering the Plugin Solar Electric vehicle as a prototype, the changes in power output due to seasonal variation and resultant impact on the total energy consumption and the consequent changes in mileage of Plugin solar Electric Vehicle is investigated for the whole year. The fuel economy of the Prototype Plugin Solar Electric vehicle is also discussed in comparison with other conventional and non-conventional fossil fuel.
\end{abstract}

Keywords: Plugin solar electric vehicle, solar photovoltaic, fossil fuel, solar energy

\section{Introduction}

There is growing concern globally, about the future energy sources, As fossil fuels are exhausting very rapidly, several studies and research have been conducted to predict entire energy reserves, it is predicted that oil and gas will be exhausted by 2042, leaving coal as the only fossil fuel [1], not considering the Shale gas reserves, as the technically recoverable shale gas for the whole world is not yet reported but It can surly support the world for some decades. Still there is no guarantee that the oil and gas price will never rise enough to high cost that will result in the socio-economical and industrial crises. Fossil fuels accounts for about more than $80 \%$ of the world energy consumption and as the oil peaking approaches the price of the oil and gas will rise rapidly, imparting great influences on the world economy [2]. There is therefore a severe need to explore alternative energy sources in order to fulfil the future requirement, it is very important to shift towards energy sources that are sustainable as well as environmentally friendly.

Above $90 \%$ of the transportation depends on the fossil fuels (Fig. 1) [3]. So the overriding of the internal combustion engine with the electric engine will have great impact on the total energy requirement and environment. The world is considering the Electric Vehicle as a future transport, and there are possibilities to fully propel the electric vehicle with solar photovoltaic energy. Moreover the deployment of the daytime charging of the Electric Vehicle with renewable photovoltaic energy is supposed to minimize the stress of the energy requirement and climatic effects. Considerable research has been carried out on the charging of electric vehicle with solar photovoltaic energy; different models and system have been reported, even a model of the solar power train have also being suggested [4]. It is conceivable to fully power the electric vehicle with renewable energy sources i.e. solar Photovoltaic.

A sustainable source of solar energy is potentially capable of meeting a significant portion of world energy required with least adverse environmental implications. Each year, $700 \times 10^{12} \mathrm{MWh}$ of solar energy is obtained from the sun by the earth. The maximum solar irradiance is received by the earth's surface is about 5 to $8 \mathrm{kWh} / \mathrm{m}^{2} /$ day, i.e., $1.5-2 \mathrm{MWh} / \mathrm{m}^{2} /$ year [5]. So the direct conversion of the solar

\footnotetext{
${ }^{*}$ Manuscript received April 18, 2016; revised July 10, 2016.

Corresponding author. Tel.: +92-345-9353351; E-mail address: sulaiman.txt@ gmail.com.

doi: $10.12720 /$ sgce.5.3.168-173
} 
energy by solar photovoltaic can be able to generate significant amount of energy that can be possibly used for transportation purposes. However, the geographical location also counts for the solar energy generation due to the intensity variation of the radiation, near the equator intensity of the radiation is comparatively higher.

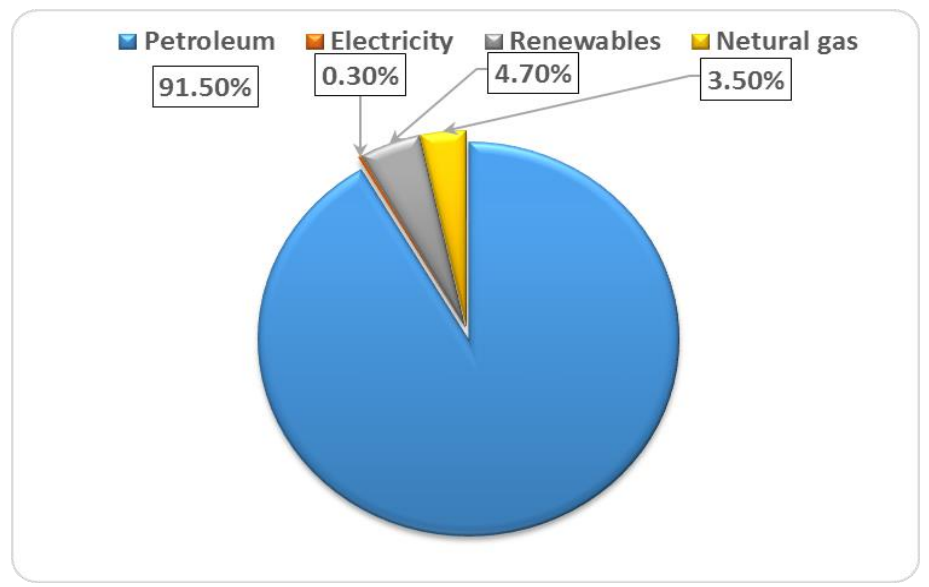

Fig. 1. Distribution of transportation etnergy consumption by source 2014 [3].

The aim of this research is to establish the feasibility of the solar energy for the passenger transportation. For this purpose a prototype of Plugin Solar Electric Vehicle was manufactured, with roof mounted Photovoltaic modules to investigate the energy added by the Photovoltaic modules and their impact on the entire fuel consumption. The generation of the power from the photovoltaic modules is measured for the whole year to investigate the seasonal changes in the total power generation of the photovoltaic modules.

\section{Plug-in Solar Electric Vehicle Design and Specification}

A prototype Plugin Solar Electric Vehicle was designed and manufactured to study the solar energy feasibility for commercial passenger transportation. The vehicle body is deliberate to be light weight to enhance its efficiency and to consume less traction power. The body of the vehicle is open structure to minimize the material and manufacturing cost along with vehicle weight (Fig. 2). The vehicle is designed for the 10 passengers, including the driver. The photovoltaic modules are insulted on the area of $4 \mathrm{~m}^{2}$ on the rooftop of the vehicle. The vehicle is designed to operate on a hard surface with maximum gradient of 25 degrees.

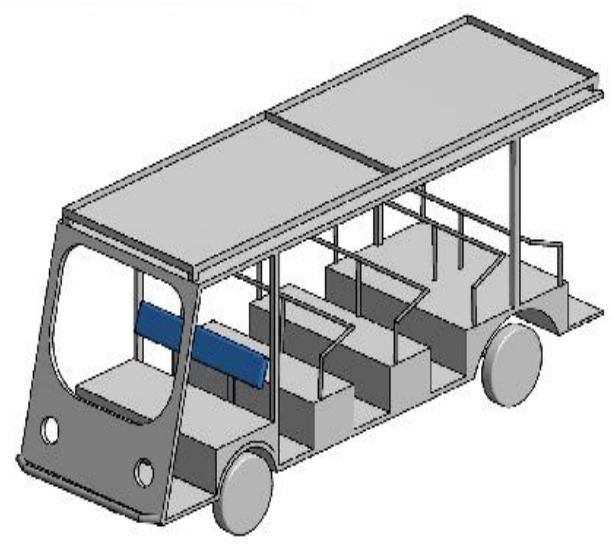

Fig. 2. Structural design of the Plug-in solar electric vehicle. 
The other specifications of the vehicle are given below (in Table 1).

Table 1. Main specification and feature of plug-in solar electric vehicle

\begin{tabular}{|l|l|}
\hline \multicolumn{2}{|c|}{ Specification of Plug-in Solar Electric Vehicle } \\
\hline Body & $\begin{array}{l}\text { frame with open structure made } \\
\text { from fiberglass and steel tubes }\end{array}$ \\
\hline Main Motor & $10 \mathrm{~kW}$, BLDC 48V \\
\hline Solar modules Area & $4 \mathrm{~m}^{2}$ \\
\hline Maximum speed & $80-100 \mathrm{Km} / \mathrm{h}$ \\
\hline Range & $50 \mathrm{Km}$ or above \\
\hline Height (with wheels) & $180 \mathrm{~cm}$ \\
\hline Ground Clearance & $\geq 150 \mathrm{~mm}$ \\
\hline Suspension & Hydraulic, leaf spring \\
\hline Tires & $145 / 70 \mathrm{R} 12$ \\
\hline Brake & Hydraulic, Disc type \\
\hline Steering & Ackerman steering (manual) \\
\hline Weight & $1200 \mathrm{~kg}$ \\
\hline Maximum Loading & $800 \mathrm{~kg}$ \\
\hline Battery Bank & $14.5 \mathrm{kWh}$ dry Gel(maintenance free) \\
\hline
\end{tabular}

The batteries of capacity $14.5 \mathrm{kWh}$ can be charged from the on-build Monocrystalline Silicon Photovoltaic modules as well as from the national grid. From the nation grid the batteries takes 6-8 hours to fully charge and charging it from Photovoltaic modules the time varies through the year according to solar intensity.

\section{Solar Energy for the Plug-in Solar Electric Vehicle}

As the Solar electric vehicle is operating in the capital city of Pakistan (Islamabad) located at latitude $33.7167^{\circ} \mathrm{N}, 73.0667^{\circ} \mathrm{E}$ longitude. So the solar Photovoltaic potential for the above mentioned locality is considered and measured to judge the seasonal variation annually from season to season (summer to winter and winter to summer). The Photovoltaic modules output were measured for the whole years from the November 2014 to October 2015.

During the drive the Photovoltaic modules are in very complex situation involved in the motion of the vehicle like fluctuating speed, shades, direction and orientation (due to the changing slops and direction), The solar radiation received by the Photovoltaic modules varies instantaneously during the drive [6]. The Experiments show that the power output of the Photovoltaic modules increase slightly in motion in comparison to stationary condition The route at which the Plugin Solar Electric Vehicle is operating is 51 $\mathrm{Km}$ round trip that is covered normally in $10-15$ mint with average speed of $25 \mathrm{~km} / \mathrm{h}$. The PSEV cover $51 \mathrm{Km}$ (one round trip) in every hours and remains stationery for the rest of time at the stop every day. There is no shades falling on Plugin Solar Electric Vehicle while driving on the route and as well as at the stop, so the vehicle is exposed to the sun for the most of the time during the day, therefore the output of the solar Photovoltaic modules are measured and reported for horizontal Photovoltaic modules at the maximum exposure to the sun throughout the year (Fig. 3, Fig. 4).

The solar Photovoltaic output is recorded by the data acquisition system form the moment the first ray of light fall on Photovoltaic modules and is converted into electric current. The reading is recorded in the Watt-hour for the whole duration. The sum of the total energy generated per day in represented in the graphs mentioned in Fig. 3.

The lowest Photovoltaic output was recorded in the month of December with the average energy generation of about $1340 \mathrm{Wh} /$ day with the least peak hours of about 3.5 to 4.5 . In the summer the rate of power generation triggered up to $2500 \mathrm{Wh} /$ day (for the photovoltaic modules installed on the vehicle). The most cloudy days were reported in the month of February and July, August resulted in the decline of the 
monthly sum of the photovoltaic power output (Fig. 4).

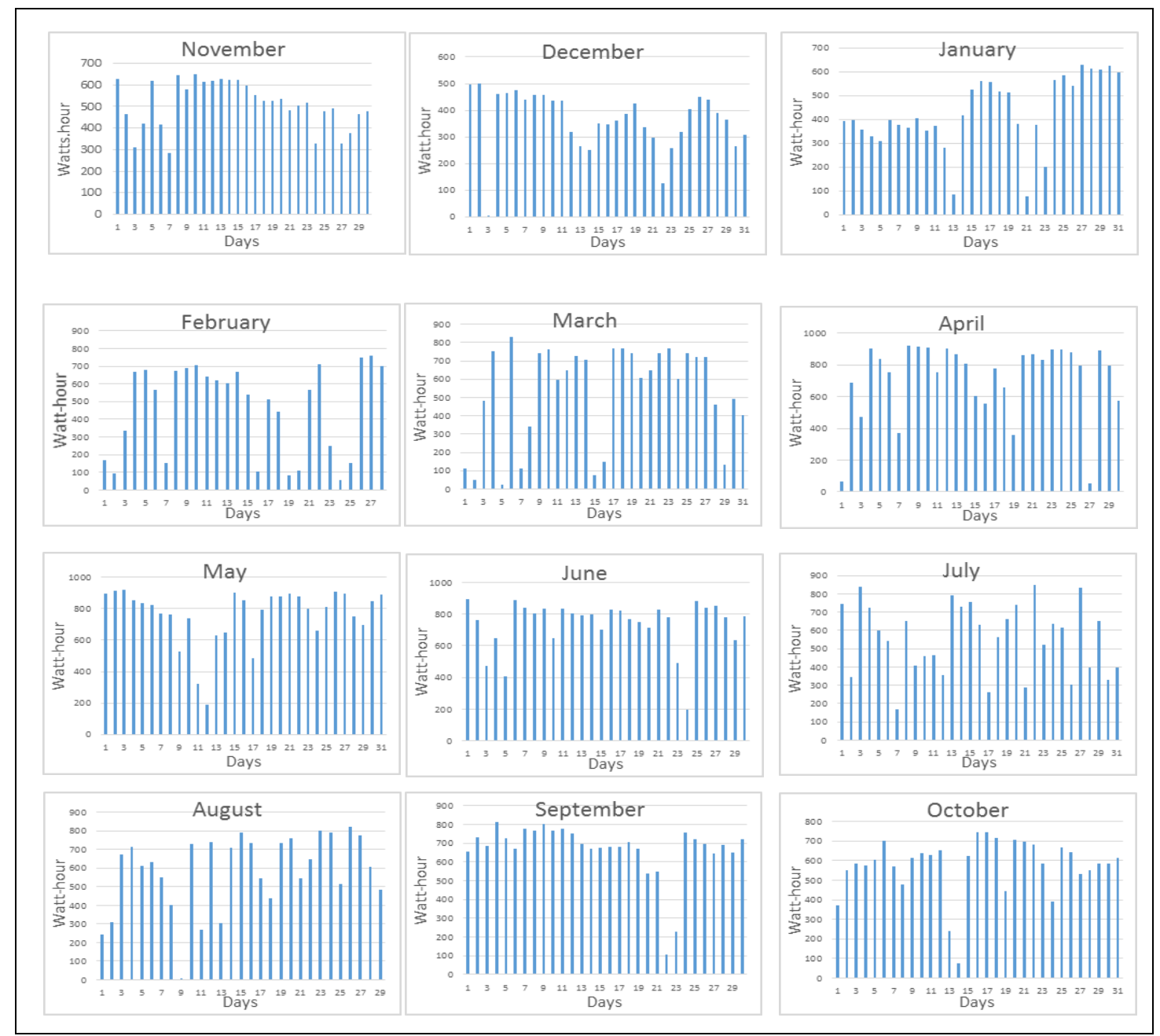

Fig. 3. Solar Energy added per day in respective months by the PV modules installed in the Plugin Solar Electric Vehicle.

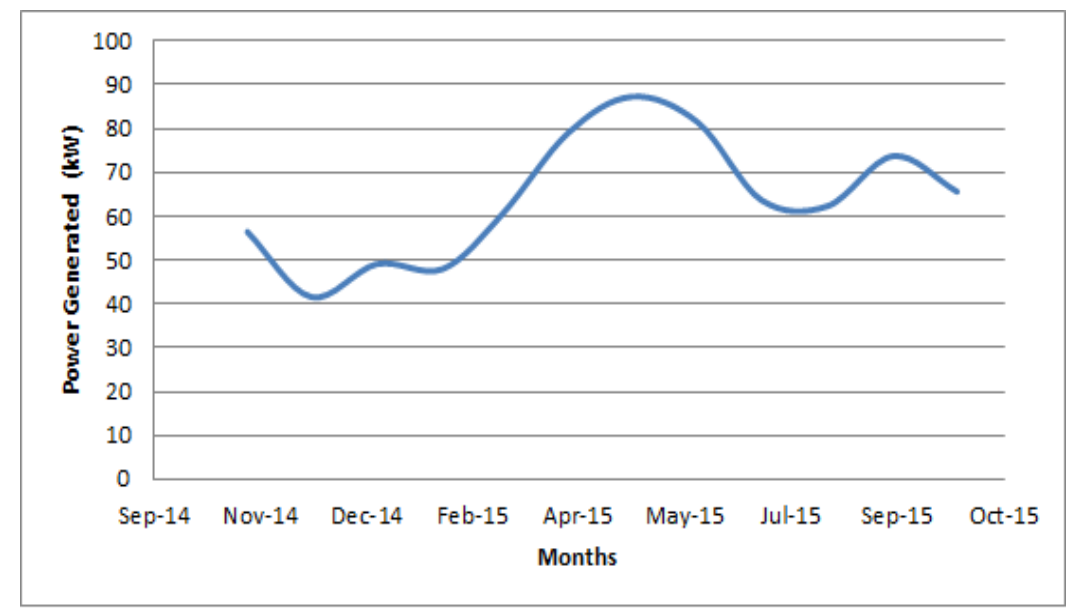

Fig. 4. Monthly sum graph of the power output of the PV modules installed in the vehicle. 


\section{Results and Discussion}

The Plugin Solar Electric Vehicle with the battery bank of about $14.5 \mathrm{kWh}$ covers $50 \mathrm{Km}$ of distance when the vehicle is fully charged from the National grid without the solar Photovoltaic contribution about $15 \%$ of the energy is lost in the Converter (AC to DC converter and charger). The energy contributed by the Photovoltaic modules varies throughout the year (as shown in Fig. 3 and Fig. 4) so the resultant additional distance covered by the vehicle also varies accordingly. The distance contributed by the Photovoltaic modules varies from $5 \mathrm{Km}$ to $10.5 \mathrm{Km}$.(Table. 2). Though the on-build photovoltaic modules are not fully capable of completely propel the Plugin Solar Electric Vehicle to any acceptable amount of distance during the day, but still contributed a substantial amount of free energy to the battery bank.

A $4 \mathrm{~m}^{2}$ of the on-board Photovoltaic device is chronicled to add, about $845 \mathrm{kWh} /$ year (from Nov-2014 to Oct- 2015) that is able to propel the Plugin Solar Electric Vehicle for the distance of about $2873 \mathrm{Km}$ for whole year. The solar Photovoltaic of the mentioned area is capable to replace the fossil fuel for the $2873 \mathrm{Km}$ for the same capacity of vehicle throughout year that will help to reduce stress on the depleting fossil fuel and add free renewable fuel that cut down the fuel cost as well as reduce the emission of Greenhouse gases produced during resultant combustion of fossil fuels.

Table 2. Average daily solar power generated by the photovoltaic modules

\begin{tabular}{|l|c|c|}
\hline Month & $\begin{array}{c}\text { Average daily Solar Energy } \\
\text { Kwh/Month }\end{array}$ & $\begin{array}{c}\text { Distance on PV added } \\
\text { Power km/Day }\end{array}$ \\
\hline Nov-14 & 2.1 & 7.0 \\
\hline Dec-14 & 1.5 & 5.0 \\
\hline Jan-15 & 1.7 & 6.0 \\
\hline Feb-15 & 1.9 & 6.5 \\
\hline Mar-15 & 2.1 & 7.5 \\
\hline Apr-15 & 2.9 & 10.0 \\
\hline May-15 & 3.1 & 10.5 \\
\hline Jun-15 & 3.0 & 10. \\
\hline Jul-15 & 2.3 & 7.5 \\
\hline Aug-15 & 2.3 & 8.0 \\
\hline Sep-15 & 2.7 & 9.0 \\
\hline Oct-15 & 2.3 & 8.0 \\
\hline
\end{tabular}

\subsection{Fuel cost analysis}

Considering the same capacity of the vehicle driven for the alternative energy sources a cost analysis has being made considering the current energy prices. If the vehicle is driven by the electric energy from the National grid the vehicle fuel economy is about $0.0334 \mathrm{USD} / \mathrm{Km}$ consider the electricity rates here in Pakistan. While on gasoline the fuel economy will be $0.0745 \mathrm{USD} / \mathrm{Km}$, for diesel it will be 0.0678 $\mathrm{USD} / \mathrm{Km}$ and for CNG it will be $0.0554 \mathrm{USD} / \mathrm{Km}$ as shown in Table 3. The free solar energy contribution varies throughout the year so the fuel economy of the solar/electric hybrid system also varies accordingly.

Table 3. Fuel Economy of the Plugin Solar Electric Vehicle in comparison with other fuel type

\begin{tabular}{|l|c|c|}
\hline Type of fuel & USD/Km & USD/Year \\
\hline Gasoline & 0.0745 & 214.03 \\
\hline Diesel & 0.0678 & 194.83 \\
\hline CNG & 0.0554 & 159.15 \\
\hline Pure Electric & 0.0334 & 96.04 \\
\hline
\end{tabular}

\subsection{Recommendation for fully solar power plugin solar electric vehicle}

The on-board Photovoltaic modules will not be able to fully power the vehicle of same capacity to 
cover the acceptable amount of distance for the whole day. Though there are possibilities for the Plugin Solar Electric Vehicle to be powered from the off-board solar energy. The Plugin Solar Electric Vehicle is operating as shuttle services in campus, which cover distance of $5.1 \mathrm{Km}$ in 10-15 minutes and stay at the stop for the $40-45$ minutes. So if the solar powered station is installed at the vehicle stop, the vehicle can be charged during its stay at the station. It will enable the Plugin Solar Electric Vehicle to be only powered from pure solar energy for the whole day. According to the real time data the $16 \mathrm{kWh}$ Solar Power Station that can be installed at area of $43 \mathrm{~m}^{2}$, considering the same Monocrystalline Solar Modules will be sufficient enough to power the vehicle around the year.

\section{Conclusion}

In this paper the particle implementation of the on-board solar Photovoltaic for a prototype Plug-in Solar Electric Vehicle is investigated. The Energy produced by the on-board solar Photovoltaic were recorded to be $845 \mathrm{kWh}$ and reported for the region of Islamabad for 12 months duration (from Nov-2014 to Oct-2015). Solar Photovoltaic of area $4 \mathrm{~m}^{2}$ installed at the rooftop of the vehicle, will power the vehicle for $2873 \mathrm{Km}$, the Impact of the resulting power on the total energy requirement and daily mileage added by the solar Photovoltaic was also reported. The impact of the varying power due to seasonal variation on the total mileage of the vehicle is extremely prominent. The fuel economy of the Plugin Solar Electric Vehicle is foremost better than conventional fuel driven vehicle. Moreover it can be concluded that the off-board fully solar powered Plug-in Solar Electric Vehicle is very much possible for the discussed scenario

\section{References}

[1] Shafiee S. When will fossil fuel reserves be diminished? Energy Policy, September 2009; 37:181-189.

[2] Shahriar S. A long-term view of worldwide fossil fuel prices. Applied Energy, March 2010:988-1000.

[3] Oak Ridge National Laboratory. Energy for transportation Data Sheet. U.S. Department of Energy; 2014.

[4] Jaffery MS. The potential of solar powered transportation and the case for solar powered railway in Pakistan. Renewable and Sustainable Energy Reviews, 2014; 39:270-276.

[5] Shaikh PH. Solar energy: topographical asset for pakistan. Applied Solar Energy, 2013:49-53.

[6] Hassan Moghbelli RV. Implementation of the movable photovoltaic array to increase output power of the solar cells. In: Proc. of International Conference on Renewable Energy for Developing Countries, 2006. 